\title{
Movilidad marginal en los asentamientos irregulares de la Zona Metropolitana Puebla-Tlaxcala. El caso de Cuitláhuac
}

Maria-de-Lourdes Flores-Lucero. Benemérita Universidad Autónoma de Puebla, Puebla, México.

María-Lourdes Guevara-Romero. Benemérita Universidad Autónoma de Puebla, Puebla, México.

Juan-Carlos Silverio. Benemérita Universidad Autónoma de Puebla, Puebla, México.

RESUMEN | La marginalidad urbana en los asentamientos irregulares (AI) dificulta la movilidad cotidiana de sus habitantes. Este problema obedece, entre otras cosas, a la débil integración de dichos conjuntos en los instrumentos de planeación de las zonas en que están insertos, y a un juego político perpetuado tanto por los gobiernos locales como por algunas organizaciones políticas, que ven en los AI un blanco fácil para satisfacer intereses partidistas. Nuestro objetivo es aportar a la reflexión sobre las dificultades de movilidad a que se ven sometidos los AI y entender sus causas fundamentales, a través del análisis del caso de la colonia Cuitláhuac de la Zona Metropolitana Puebla-Tlaxcala. Entre los principales resultados destacan, por una parte, el control que ejercen algunos organismos políticos en los AI, que alargan los procesos de apoyo para permanecer más tiempo en el poder, prolongando la marginalidad urbana de dichos asentamientos; y por otra, el desarrollo de formas alternativas de movilidad marginales por parte de los habitantes, con algunos matices de sustentabilidad.

PALABRAS CLAVE $\mid$ movilidad, vulnerabilidad, campamentos.

ABSTRACT | The urban marginality in slums difficult daily mobility of its habitants. This problem due to the weak of integration in the planning instruments of these areas, and to a political game perpetuated by local governments and by some political organizations that see in the slums an easy political target to satisfy their interests. Our objective is to contribute to the reflection on the mobility difficulties in irregular settlements (IS) and understand its root causes, analyzing the case of Cuitláhuac neighborhood in the Metropolitan Area Puebla-Tlaxcala. The main results are the control exercised by some political organizations in the IS, who make longer the support processes for extend their control in slums, extending in time their urban marginality; and that the inhabitants develop alternative forms of marginal mobility, but with some nuances of sustainability.

KEYWORDs | mobility, vulnerability, slums.

Recibido el 5 de octubre de 2020, aprobado el 3 de noviembre de 2020.

E-mails: M. Flores Lucero, maria.flores@correo.buap.mx | M. Guevara-Romero, lourdes.guevara@correo.buap.mx | J. Silverio, carlos.

silverio@alumno.buap.mx 


\section{Introducción}

La marginalidad en los asentamientos irregulares (AI) es común, fruto de las formas ilegales de apropiación del territorio en zonas periféricas. Esto lleva a una tendencia de crecimiento marginal, principalmente en países en vías de desarrollo, que para el 2030 -de acuerdo con el Programa de las Naciones Unidas para el Desarrollo (PNUD, 2010)- llevará a 2 millones de personas a vivir en barrios marginales. También es común que la vulnerabilidad urbana se agudice en los asentamientos irregulares de las periferias debido a factores como las carencias infraestructurales, y a otros de carácter político, que tienden a agudizar sus problemáticas e inhibir su desarrollo urbano.

Desde los años ochenta, en México, algunas ciudades, como Puebla, han crecido de manera acelerada, transformándose en zonas metropolitanas con una periferia dispersa, que presenta problemáticas urbanas poco atendidas (Aguilar, 2002) y una fuerte necesidad de infraestructura para la movilidad. En este sentido, la planeación para las zonas metropolitanas desempeña un rol central en la generación de políticas que fomenten el desarrollo de infraestructura para la movilidad y sistemas articulados e incluyentes para desplazarse dentro del territorio. Sin embargo, el discurso de Sobrino (2003) sigue presente cuando dice que en México no se ha creado un marco normativo suficiente que promueva la planeación territorial desde una perspectiva metropolitana. A ello se suma, según Kunz y González (2019), la dificultad de alinear intereses entre las unidades territoriales y las agendas políticas de los diferentes actores que participan. Uno de los efectos de esta debilidad es que la infraestructura para la movilidad no suele ser prioritaria en las demandas ciudadanas de los habitantes de las zonas periféricas. Además, la débil integración a la planeación de los asentamientos irregulares facilita las disfuncionalidades viales, de accesibilidad y movilidad, mismas que van siendo atendidas mediante acciones remediales precarias (pavimentaciones de mala calidad, rellenado de los baches en las calles con cascajo, alquitrán, etcétera) tendientes a permitir la movilidad al interior de dichos asentamientos. En temporada de lluvias, la dificultad para moverse se acentúa y, en algunas ocasiones, la posibilidad de trasladarse se paraliza.

En términos políticos, en México es habitual la presencia de grupos organizados que apoyan a partidos políticos, los que, a cambio de promesas de mejoramiento urbano que regularmente llegan a cuentagotas y con una cuestionable puesta en práctica urbana, manipulan a las organizaciones vecinales provenientes de zonas con vulnerabilidad urbana, como las periferias marginales.

Es en este contexto donde los AI de la Zona Metropolitana Puebla-Tlaxcala (ZMPT), desenvuelven su vida cotidiana. Esta zona es la cuarta metrópoli de México, ya que cuenta con una población de 2.728.790 habitantes sobre una superficie de $2.204,34 \mathrm{~km}^{2}$ (Instituto Nacional de Estadística y Geografía [INEGI], 2010), ubicada en la zona centro del país. Aquí, el gobierno local se ha limitado a dotar a los AI de servicios básicos (agua, luz, drenaje y alcantarillado), siempre y cuando hayan alcanzado el 50\% de consolidación (Gobierno del Estado de Puebla, 2003). Esto contradice en todas sus aristas los principios de movilidad sustentable establecidos por la Organización de las Naciones Unidas (2017), en los cuales se establece, 
entre lo más destacado, que los gobiernos deberán generar las condiciones para asegurar a todos los habitantes el derecho equitativo a moverse de forma segura y accesible, así como brindar los sistemas de transporte que les permitan llegar a sus diferentes destinos cotidianos.

Por su parte, los habitantes de los AI suelen organizarse para dar respuestas inmediatas a sus necesidades cotidianas de movilidad, respuestas alternativas como el auto colectivo y el compartido, que -a pesar de sus condiciones de precariedad- se decantan por algunas de las características de la movilidad sustentable. Es mediante el estudio de la colonia Cuitláhuac que exponemos las condiciones marginales de movilidad en la periferia marginal de la Zona Metropolitana Puebla-Tlaxcala. La finalidad es enriquecer las reflexiones sobre las causas fundamentales que han contribuido a agudizarlas, así como reconocer las respuestas alternativas que dan los habitantes y que podrían incorporarse, para su mejoramiento, en las agendas políticas locales.

La metodología es cualitativa y está basada en la investigación-acción. Es importante aclarar que, debido a que Cuitláhuac no ha sido reconocido por ningún municipio, no contábamos con información estadística ni cartográfica, por lo que fue necesario generarla. Las principales técnicas utilizadas fueron:

a. Análisis documental sobre fuentes bibliográficas que definen las características de movilidad sustentable y la vulnerabilidad urbana en materia de infraestructuras, y sobre instrumentos oficiales locales, estatales y federales relativos al mejoramiento de asentamientos irregulares y la movilidad en Puebla; particularmente, el Programa de Desarrollo Urbano del Municipio de Puebla y el Programa de Incorporación de Asentamientos Humanos Irregulares al Desarrollo Urbano Sustentable.

b. Recorridos de campo. Se realizaron cuatro recorridos de campo en la colonia y sus alrededores que nos ayudaron a realizar el diagnóstico sobre las condiciones urbano-territoriales y las formas de movilidad en Cuitláhuac.

c. Encuestas a 70 vecinos cuyos rangos de edad oscilaron entre los 15 y 60 ańos. Predominaron las amas de casa, pero también se encuestó a jóvenes, padres de familia y a una persona de la tercera edad. Así pudimos identificar aspectos socioeconómicos como actividad laboral, salario mensual, perfil profesional, nivel de estudio, etcétera. En cuanto a la movilidad, obtuvimos información sobre medios, costos, destinos y dificultad para transitar al interior de la colonia.

d. Entrevistas semidirigidas e historias de vida, aplicadas a actores clave de la colonia: el presidente, dos miembros de la mesa directiva, dos habitantes que dan el servicio de transporte con sus camionetas, un taxista y tres fundadores de la colonia. Las entrevistas sirvieron para entender y profundizar tres aspectos centrales: i) la percepción de los entrevistados sobre las condiciones urbanas en general, y las condiciones y medios de transporte utilizados en la colonia; ii) la gestión ante las autoridades locales para mejorar sus condiciones de movilidad y contar con el servicio de transporte público dentro de la colonia, así como para 
conocer la respuesta que han tenido por parte de las autoridades y si esta ha sido condicionada de alguna manera; iii) aspectos organizacionales, a fin de conocer cómo están organizados internamente los habitantes, cuáles son sus principales demandas, e identificar las estrategias que han desarrollado para mejorar su movilidad. Las historias de vida nos ayudaron a entender el proceso histórico del que han sido actores para obtener el servicio de transporte público, y otros con los que actualmente cuenta la colonia. A través del presidente, obtuvimos el registro del número de habitantes de la colonia.

e. La observación participante. Se asistió a tres reuniones de tres manzanas y cinco reuniones del pleno de la colonia con los integrantes de la mesa directiva. Ellas nos sirvieron para identificar sus principales demandas en el conjunto de la colonia y entender sus problemáticas de organización para la gestión de servicios.

\section{Asentamientos irregulares y vulnerabilidad infraestructural para la movilidad urbana}

Las infraestructuras destinadas a la movilidad urbana son fundamentales para el desarrollo urbano en sus diferentes escalas, empezando por la célula básica de la ciudad: el barrio. En países en vías de desarrollo, las periferias suelen presentar serias deficiencias de conectividad y accesibilidad a la ciudad central, principalmente en los barrios marginales. De acuerdo con Leibler y Brand (2012), los más pobres se enfrentan a restricciones en cuanto al número de viajes que pueden realizar diariamente, lo que a su vez se traduce en la limitación del mejoramiento de la vida urbana y de la participación de las personas en ella; es decir, se coarta el acceso a los recursos de la ciudad.

La Organización de las Naciones Unidas (2015), reconociendo los problemas de marginalidad en la movilidad en países en desarrollo, propone, entre sus metas del objetivo "ciudades y comunidades sostenibles"; proporcionar para el 2020 acceso a sistemas de transporte seguros, asequibles, accesibles y sostenibles para todos, y mejorar la seguridad vial. Esto no ha sido posible aún en países como México, donde la situación generada por la pandemia Covid-19 ha agudizado y puesto de relieve los problemas de movilidad y accesibilidad de los grupos más vulnerables, particularmente los residentes en las zonas periféricas.

Por otro lado, las formas de crecimiento centro-periferia en zonas metropolitanas dispersas mal planeadas "se encuentran en el centro de implantación de modelos de desarrollo urbano ambientalmente, socialmente y económicamente insostenibles" (Programa de las Naciones Unidas para los Asentamientos Humanos [ONUHabitat], 2013, p. 27), que tienden a romper la conexión del entramado urbano y acrecentar las desigualdades sociales. Desde la perspectiva de Borja (2014), las zonas metropolitanas son territorios de urbanización discontinua, fragmentada, con espacios públicos pobres y sometidos a las dinámicas privatizadoras, caracterizados por la segregación socioespacial. Habitar en ellas y tener acceso al trabajo, vivienda, cultura, formación y ocio, requiere de un relativamente alto nivel de ingresos, así como de un efectivo derecho a la movilidad. Las relaciones sociales en zonas 
metropolitanas se han empobrecido para la mayoría de la población, debido a la precarización del trabajo y el tiempo gastado en la movilidad cotidiana.

Suzuki et al. (2014) destacan que la movilidad sustentable deberá, desde una planeación con visión incluyente, favorecer los usos de suelo mixtos, la creación de zonas más densas a lo largo de los corredores, los espacios urbanos de alta calidad, así como el uso de medios no motorizados y formas de traslado colectivas para reducir la movilidad en autos privados. Además, los líderes políticos han ido reconociendo que las ciudades que gozan de altos niveles de movilidad y accesibilidad también son ciudades económicamente más productivas y mejores lugares para vivir (Susuki et al., 2014, p. 39). Asimismo, los planes locales promueven cada vez más la idea de desarrollar ciudades más compactas y complejas, en las cuales -como indica Da Cunha (2005) - se dan numerosas ventajas medioambientales, económicas y sociales, ya que se favorecen los desplazamientos peatonales (walkable city) y formas de movilidad no motorizada, el incremento de rutas verdes (greenways), un ambiente agradable y accesible en su espacio público, tanto para los trayectos como para permanecer en ellos (livable city); es decir, se impulsa la disminución del gasto energético y la creación de espacios públicos donde los habitantes puedan reconocerse e identificarse. Con ideas como estas se están repensando las formas de movilidad, en la búsqueda de un transporte público eficiente y de calidad, traslados no motorizados, y poniendo al usuario al centro de estos sistemas.

Los planteamientos de movilidad sustentable señalados distan abismalmente de las condiciones de movilidad en asentamientos irregulares, los cuales llevan intrínseca la vulnerabilidad en sus diferentes matices; de hecho, nacen vulnerables. La vulnerabilidad urbana, entendida por Alguacil et al. (2014) como "la potencialidad de que la población de un determinado espacio urbano concreto sea afectada por alguna(s) circunstancia(s) adversa(s)" (p. 77), de manera que determinadas condiciones de riesgo, fragilidad y desventaja hacen posible la entrada de una situación crítica a la población, se presenta de diversas maneras en los AI. Una de ellas está enfocada en que "el trazo viario en estos asentamientos no cumple con la lógica de estructuración del espacio habitacional como los derechos de vía, anchos de calle, que dote de las formas de accesibilidad mínimas" (Vázquez et al., 2015, p. 107); a ello se suma que la mayoría no cuenta con la infraestructura básica para la movilidad: banquetas (aceras), pavimentación, alumbrado público, drenaje, alcantarillado y mobiliario. Esta situación se agrava con el hecho de que, en Puebla, el derecho a la urbanización no considera la implementación de muchas de las condiciones necesarias para la movilidad, ya que el municipio se remite a dar los servicios de agua, luz, drenaje y alcantarillado, aunque por lo general son los dos primeros los que se dotan en el corto plazo, mientras el drenaje y alcantarillado pueden tardar décadas (Flores, 2016). En estas condiciones, el acceso de las unidades de transporte público a los AI se vuelve imposible, dejándolos al margen de dicho servicio. Esto contradice las recomendaciones de la Nueva Agenda Urbana sobre la importancia de que los gobiernos fomenten desde sus instrumentos de planificación, basados en un enfoque integral, la interacción y conectividad territorial de sus ciudades y zonas periurbanas (ONU, 2017). 
En las ciudades se multiplican las necesidades de movilidad y, al mismo tiempo, se generan numerosas situaciones de vulnerabilidad para las personas, a la vez que los espacios urbanos (o semiurbanos) son objeto de agresiones naturales como las inundaciones y deslizamientos, entre otros, limitando y poniendo en riesgo la circulación para los usuarios (Rey \& Cardozo, 2007). Nos referimos a la llamada vulnerabilidad física e infraestructural, concerniente a aquellos asentamientos humanos localizados en zonas alejadas de la ciudad consolidada y carentes de servicios e infraestructura básicos (Wilches-Chaux, 1989), situación que incrementa las posibilidades de desastre natural, pero que también influye negativamente en la seguridad, accesibilidad y movilidad cotidiana de los habitantes. Para disminuir las condiciones de vulnerabilidad y, en consecuencia, de marginalidad, destaca el papel crucial que desempeña el espacio habilitado con infraestructuras para facilitar la vida cotidiana y generar relaciones de equidad en materia urbana. En este sentido, las buenas condiciones de elementos urbanos como las calles, banquetas, mobiliario, red y servicio de drenaje, alcantarillado y energía eléctrica, vegetación, así como el servicio de transporte público -entre lo más destacado-, en su conjunto permitirían a los habitantes realizar sus desplazamientos diarios de manera fácil y confortable.

Disminuir la vulnerabilidad depende de la capacidad de respuesta en cada sociedad. En el caso de la movilidad, el rediseño de la estructura urbana y la redistribución en las infraestructuras y usos del suelo no solo permiten reducir tal condición, sino que crean ambientes propicios para la organización y desarrollo de las actividades humanas (Rey \& Cardoso, 2007). La capacidad de respuesta, particularmente para las zonas periféricas, está fuertemente vinculada a la existencia de sistemas de planeación y gestión locales con visión incluyente y resiliente. En este sentido, los gobiernos locales son cruciales para asegurar la inclusión desde la planeación de los asentamientos irregulares y -como anota ONU-Habitat (2013) - garantizar que las inversiones para el desarrollo de infraestructuras para la movilidad se realicen donde más se necesitan, basados en el principio de accesibilidad que asegura que todas las personas disfruten de manera equitativa del acceso a los bienes y servicios básicos. Así, la planeación y las políticas públicas son fundamentales para favorecer prácticas sustentables que incidan en la disminución de la segregación socioespacial mediante la distribución equitativa de los bienes y servicios en las ciudades. Desde esta perspectiva, como anota Borja (2014), la planeación ayudaría a asegurar, sobre todo a los sectores pobres de la población, el salario indirecto; es decir, el espacio público, los bienes y servicios que ofrece la ciudad, el equipamiento, un medioambiente de calidad, grados aceptables de seguridad, acceso a la educación, sanidad, cultura, ocio, deporte y, mediante ellos, incentivar la integración social y disminuir la brecha de la desigualdad social.

Por otra parte, para implementar planes de movilidad sustentable son necesarias formas de gobernanza donde las instituciones y sus normativas sean sólidas, de manera que se puedan detectar e impedir procesos opacos en la gestión de acciones para el mejoramiento de la movilidad. Esto representa un reto mayor en los países en desarrollo, particularmente en las áreas periféricas que han quedado al margen de las acciones gubernamentales y se han vuelto territorio de nadie y de todos. De nadie, porque en muchas ocasiones no son reconocidas por los gobiernos municipales 
debido a la falta de regularización de la tenencia de la tierra, situación que se traduce, de acuerdo con Fernandes (2011), en que los habitantes de estas zonas no puedan ejercer sus derechos ciudadanos básicos. De todos, porque en tiempos electorales representan un jugoso espacio para ganar votos a cambio de promesas de campaña que difícilmente se llegan a materializar. En este sentido, "las formas tradicionales de clientelismo político mediante las cuales los dirigentes [políticos] realizan promesas electorales para resolver los problemas que afectan los asentamientos informales, tienden a perpetuar la informalidad" (Fernandes, 2011, p. 8).

\section{Movilidad en la periferia de la Zona Metropolitana Puebla-Tlaxcala}

En la Zona Metropolitana Puebla-Tlaxcala (ZMPт) se realizan 3.561.312 viajes diarios, de los cuales el $72 \%$ corresponde a transporte público y el $28 \%$, a automóvil (Periódico Oficial del Estado de Tlaxcala, 2013). El costo de un viaje en transporte público es de 8 pesos $\left(0,40\right.$ USD $\left.^{1}\right)$. Es importante aclarar que no existe la forma de pago multimodal, lo que multiplica los costos de traslado.

La movilidad en los asentamientos irregulares periféricos de la ZMPT representa un problema mayor que difícilmente es atendido por las autoridades municipales, las cuales, según señala Luna (2019), no han seguido normas de planeación, de manera que los elementos urbanos relacionados con las vías de comunicación y el transporte público presentan notorio desorden. Diversos autores (Bazant, 2004; Flores, 2017; Patiño, 2004) se refieren a la marginalidad de las infraestructuras urbanas en las zonas periféricas, rasgo que dificulta la movilidad cotidiana de sus habitantes.

Las leyes, en sus diferentes niveles, destacan la importancia de generar las condiciones necesarias para el desarrollo habitable de los asentamientos humanos. En el marco federal, la Ley General de Asentamientos Humanos (2020), en su artículo $2^{\circ}$, establece que "todas las personas, sin distinción de sexo, raza, etnia, edad, limitación física, orientación sexual, tienen derecho a vivir y disfrutar ciudades y Asentamientos Humanos en condiciones sustentables, resilientes, saludables, productivos, equitativos, justos, incluyentes, democráticos y seguros"; señala al respecto que, para ello, se deberán coordinar el gobierno federal con los estatales y municipales para la ejecución de acciones, obras e inversiones en materia de infraestructura, equipamiento y servicios urbanos, incluyendo las relativas a la movilidad y a la accesibilidad universal (artículo 10, fracción xv). Por su parte, la Ley de Desarrollo Urbano Sustentable del Estado de Puebla (2003) dice, en su artículo 113, que los Programas de Incorporación de Asentamientos Humanos Irregulares al Desarrollo Urbano Sustentable deberán reordenar las áreas de los centros de población deterioradas física o funcionalmente; coadyuvar al crecimiento ordenado de los centros de población; ordenar la consolidación de los desarrollos y localidades de acuerdo con los programas de ordenamiento territorial; y promover la participación de los sectores privado y social en las diferentes etapas de la incorporación de los asentamientos al desarrollo urbano. No obstante, estos programas se limitan a dotar de la infraestructura básica (agua potable, energía eléctrica y drenaje, alcantarillado) que, 
por lo general, llega en el largo plazo debido a que, para tener derecho a la incorporación, el artículo 115, fracción III, dice que las zonas deberán contar con una densidad de construcción no menor al 50\% (Gobierno del Estado de Puebla, 2003). Esto muestra claramente la falta de anticipación del mejoramiento urbano en estas zonas, coadyuvando, paradójicamente, a incrementar la vulnerabilidad urbana al establecer con dicho condicionamiento que el crecimiento marginal avance hasta adquirir la posibilidad del derecho a los servicios básicos.

Aunque el Programa Municipal de Desarrollo Urbano Sustentable de Puebla (Actualización 2016) plantea, dentro de sus estrategias de mediano plazo, la integración territorial para articular las zonas conurbadas (periféricas) a fin de mejorar la movilidad en la zona metropolitana, sus acciones han sido muy limitadas. Además, por el momento, varias de ellas no han podido materializarse, como la ampliación de la línea 2 del metrobús, que serviría a las colonias del sur del municipio de Puebla. En este sentido, los estudios de Silverio (2017) sobre la cobertura del transporte público en Puebla señalan la desatención en la demanda que se origina ante el crecimiento urbano descontrolado, particularmente de los asentamientos irregulares ubicados en el sector sur de la ZMPT.

Así pues, aunque existen normativas nacionales, estatales y locales que en lo general promueven la integración de movilidad en todo el territorio y accesible para todos los habitantes, no logran concretarse en objetivos y acciones incluyentes, ya que invisibilizan principalmente a los asentamientos irregulares. No omitimos que los asentamientos irregulares son excluidos legalmente del derecho a la urbanización cuando están en su etapa de formación, como se observa en la Ley de Desarrollo Urbano Sustentable del Estado de Puebla (Gobierno del Estado de Puebla, 2003), limitando su incorporación a la planeación urbana.

\section{Dificultad para la dotación de servicios básicos}

Ante la dificultad legal de obtener los servicios básicos, los asentamientos irregulares recurren con frecuencia a grupos organizados para aliarse con ellos y negociar (presionar) con la administración en curso los servicios básicos. Una de las organizaciones más presentes en estas zonas es Antorcha Campesina, que en los años ochenta fue adherida al Partido Revolucionario Institucional (PRI) como una agrupación agraria y cuyos orígenes ideológicos se basan en mejorar las condiciones de los pobres, constituyéndose así en el medio para que dichos sectores plantearan sus demandas ante los poderes públicos (Córdova, s.f.). Mastretta (2017) la define como una maquinaria compleja y controvertida, de movilización de masas ciudadanas pobres, especializada en administrar (negociar) las demandas básicas de vida, como vivienda, educación, salud, trabajo, regularización de tierras, dotación de servicios urbanos, equipamientos y transporte colectivo, entre otras. Los estudios de Godoy (2014) muestran el control que Antorcha Campesina tiene sobre sus agremiados, al detectar dos valores que la organización ve en ellos, la fe y la obediencia, cuyo incumplimiento desemboca en la pérdida de militancia de sus miembros, ya que el movimiento busca partidarios leales a cambio de la satisfacción de sus necesidades. 
Según Patiño (2004), en el municipio de Puebla los ejidatarios, ${ }^{2}$ ante el temor de ser expropiados, decidieron establecer las normas de urbanización de sus tierras agrícolas, llegando a acuerdos con organizaciones inquilinarias, partidos de izquierda y organizaciones populares y campesinas. Así, ante la inseguridad respecto de la propiedad de los terrenos ejidales, la falta de reconocimiento jurídico territorial municipal y la exclusión del derecho a la dotación de los servicios básicos, algunos asentamientos irregulares en Puebla suelen adherirse a Antorcha Campesina.

Por otro lado, la capacidad de gestión del gobierno local ha sido superada por el aumento de los AI. "Esta incapacidad de gestión se ve reflejada también en la falta de coordinación entre los municipios colindantes quienes, en general, aprovechan momentos políticos electorales para prometer, sin ninguna garantía, el mejoramiento de los asentamientos irregulares (principalmente de los servicios básicos) a cambio del voto" (Flores, 2017, p. 15).

Tanto las conveniencias gubernamentales como la de grupos organizados con fines políticos que ayudan a gestionar la urbanización en los AI, lentamente y bajo un estricto control de la organización vecinal, han sido clave para su estancamiento y rezago urbanos, ya que, a mayor tiempo de marginalidad urbana, mayor tiempo de manipulación y control.

\section{Cuitláhuac, el rostro de la movilidad marginal}

La colonia Cuitláhuac es un asentamiento irregular de aproximadamente 16,5 hectáreas, ubicado al surponiente de la Zona Metropolitana Puebla-Tlaxcala (Figura 1), y que en la actualidad cuenta con 400 habitantes, aproximadamente. Tiene su origen en 2010, cuando la organización Antorcha Campesina negoció la compra de los terrenos con los líderes del municipio de San Andrés Azumiatla, ${ }^{3}$ al cual pertenecían. Al ser un asentamiento irregular y encontrarse en los límites del municipio de Puebla, Cuitláhuac no ha sido reconocida ni por el municipio de Puebla, ni por el de San Andrés Azumiatla, a pesar de pertenecer al padrón electoral de este último. Con ello se ha dificultado la gestión para desarrollar obras destinadas al mejoramiento de la colonia, mismas que se han negociado principalmente con el municipio de Puebla.

De acuerdo con nuestras encuestas, la población predominante es de matrimonios jóvenes, con edades entre 15 y 30 años, que han formado familias de cuatro personas en promedio. La mayoría de la población trabajadora se dedica a la construcción y tiene un salario promedio de 5.000 pesos mensuales (251 USD), es decir, poco menos de la mitad del ingreso promedio para profesionistas en Puebla, que es de 10.250 pesos mensuales (514 USD) (UNIÓN, 2020).

El ejidatario, de acuerdo con la Ley Agraria (actualización 2018), sección segunda, es un sujeto agrario integrante del núcleo ejidal (tierra comunal), que tiene el derecho de uso y disfrute de sus parcelas. También tiene la facultad de designar a quien deba sucederle en sus derechos sobre la parcela. Véase Cámara de Diputados del H. Congreso de la Unión (2018).

3 De acuerdo con el Consejo Nacional de Población (CONAPO, 2010), tiene un grado de marginación alto. 
FIGURA I | Ubicación de la colonia Cuitláhuac

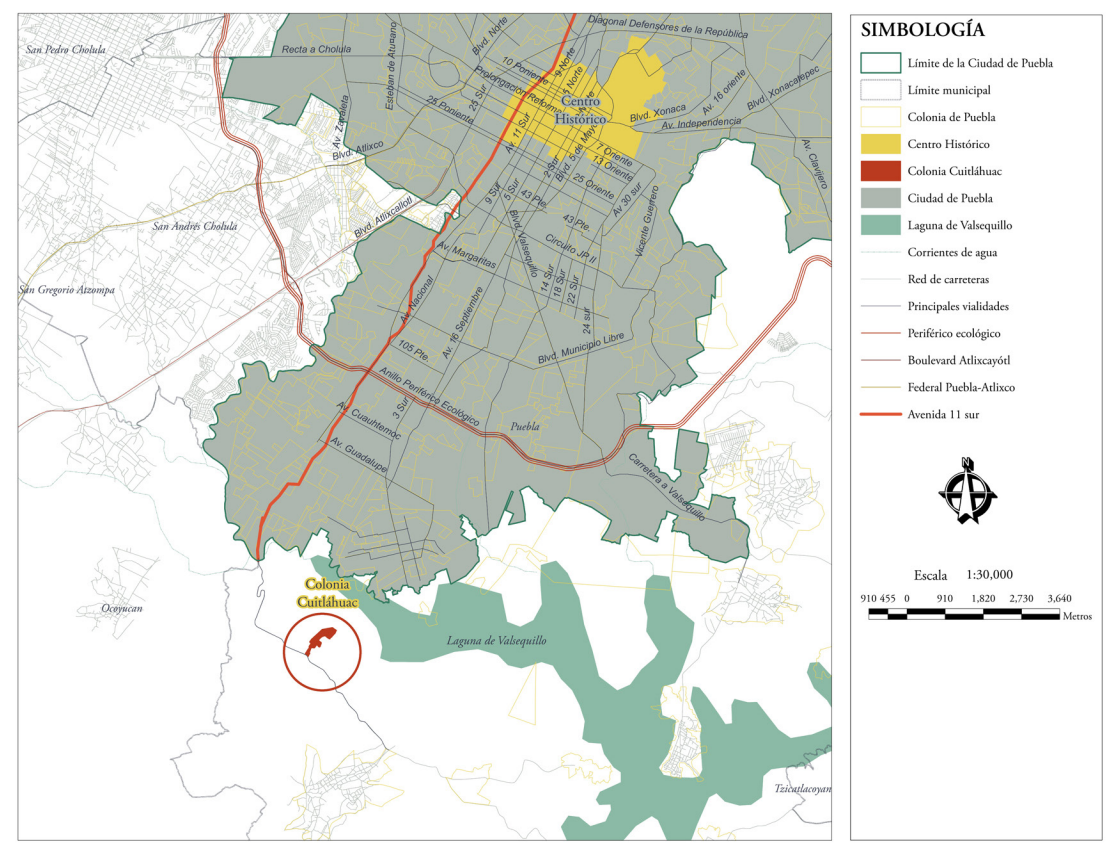

FUENTE: ELABORACIÓN PROPIA CON BASE EN EL MARCO GEOESTADÍSTICO, VÍAS DE COMUNICACIÓN DE PUEBla (INEGi, 2020) E IMAGEN DE GOOGLE EARTH, 2020

La lotificación general de la colonia, que actualmente es de 50 predios, la llevó a cabo Antorcha Campesina, y aunque la traza intenta ser reticular, las lotificaciones y sublotificaciones se van desarrollando a lo largo del tiempo de acuerdo con los intereses de cada familia y de AC. Los únicos terrenos para usos comunes, como equipamientos y espacios públicos, son los destinados a la capilla (aunque hasta la fecha no ha sido construida), una cancha deportiva y la oficina de la colonia.

Después de una década, la única infraestructura presente en toda la colonia es la red eléctrica, de la cual, sin embargo, solo está en servicio el $60 \%$. El agua potable la compran, ya que no se concluyeron las obras para la perforación de un pozo y una torre de agua para suministrar dicho recurso. Diariamente pasa un camión que vende el agua para uso doméstico: $1.000 \mathrm{~m}^{3}$ cuestan 18 pesos (0,9 usD); y también pasan camiones que venden el agua para beber en garrafones de 20 litros, con un costo de 10 pesos (0,5 USD). Respecto de la infraestructura para el drenaje, cuentan con el 50\% de avance, pero no funciona, de manera que todas las viviendas tienen al interior fosas sépticas con capacidad de hasta $10 \mathrm{~m}^{3}$. No hay servicio de alcantarillado y las calles están sin pavimentar y sin banquetas, dificultando la movilidad principalmente durante los meses de junio a octubre, cuando la intensidad pluvial es mayor (Secretaría de Desarrollo Social [sedesol] \& Gobierno del Municipio de Puebla, 2012) (Figura 2). 
FIGURA 2 | Deficiencia de infraestructura y encharcamientos

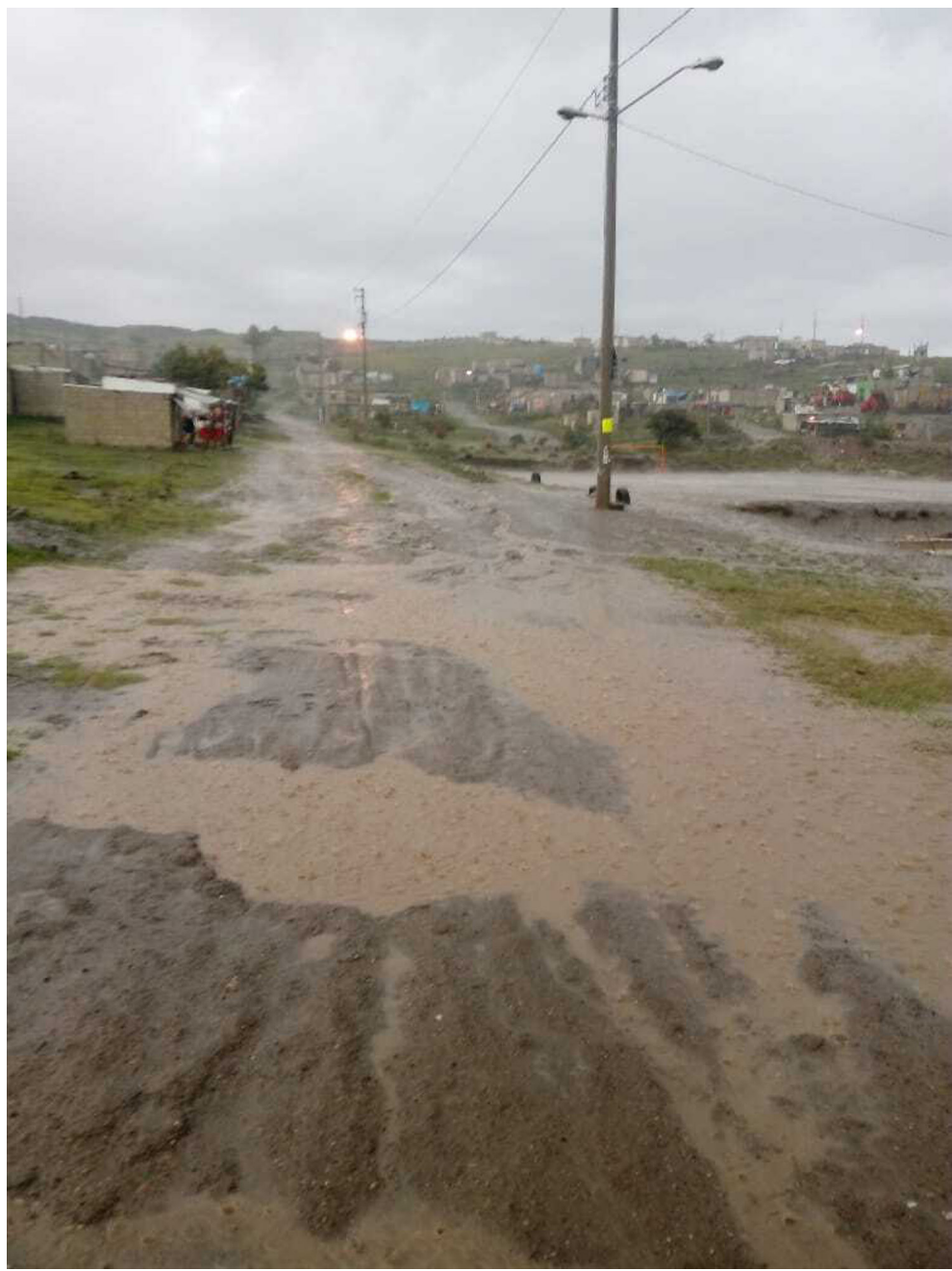

FUENTE: FOTOGRAFÍA DE LOS AUTORES, JULIO, 2020

\section{La difícil movilidad cotidiana}

Al interior de la colonia la movilidad suele ralentizarse debido a la deficiencia de infraestructuras, situación que empeora en temporada de lluvias; por las mismas razones, no entra el transporte público. El 60\% de los habitantes utiliza el autobús como único medio de transporte. Solo existe una ruta cercana a la colonia que circula sobre la prolongación de la avenida 11 Sur (Figura 3), un servicio de autobús (Ruta S5) que conecta a esta y otras colonias con el centro de la ciudad y cuya frecuencia de paso oscila entre los 10 y 15 minutos. Para llegar a sus destinos finales, el $40 \%$ de los habitantes suele combinar el autobús con otros medios, como taxi colectivo (que no circulan con licencia oficial, es decir, son ilegales, y mejor conocidos 
como "taxis pirata"), compartir auto (aunque pocos tienen), moverse en bicicleta (casi no la utilizan debido a las malas condiciones de las vialidades), o caminar; esta última es la opción más común, principalmente para los más jóvenes, ya que significa ahorro en el costo de traslado. Las personas que se ubican en el punto más lejano de la 11 Sur suelen caminar hasta la parada de autobús, traslado que, cuando las condiciones climatológicas son favorables, toma aproximadamente 15 minutos, pero en temporada de lluvia se alarga a alrededor de 20 minutos. Algunos terrenos se ubican cerca de una barranca, sobre pendientes del $15 \%$ por las cuales la circulación es muy difícil, a veces imposible. Los vecinos más afectados son los de la tercera edad, como lo ratifica el siguiente comentario:

Para salir de mi casa hasta la parada del camión me tardo 20 minutos, más o menos, y eso si voy acompańada de mi nieto. A veces tengo que llevármelo, cuando me siento muy mal de salud y voy a la clínica de Azumiatla para mis consultas. Imagínese cuando hace calor: estoy con bochorno en todo el camino y, llegando a la parada, ya estoy más que sofocada. Está más feo cuando es tiempo de lluvia; me tardo más de media hora, voy a paso lento porque me vengo atascando en el lodo y con miedo a caerme. (Com. pers., 21 noviembre 2018)

Sus principales destinos se sitúan en un radio de $6 \mathrm{~km}$, donde se encuentran un centro de salud, la cabecera municipal de San Andrés Azumiatla (aquí acuden por cuestiones de salud, abasto, escuela, y a los días de plaza), la zona residencial Lomas de Angelópolis y un jardín de niños. El centro histórico es un destino al que concurren para trabajar, abastecerse y asistir a la escuela, pocas veces para fines recreativos (Figura 3). De todos ellos, el principal punto de destino es la zona residencial Lomas de Angelópolis, ubicada a unos $6 \mathrm{~km}$, donde los hombres trabajan en la industria de la construcción (albañilería, plomería, acabados, etcétera) y las mujeres, como empleadas domésticas. Su tiempo regular de traslado es de aproximadamente una hora, ya que deben transbordar, y a veces se puede prolongar hasta hora y media debido a las largas esperas para tomar el autobús.

De acuerdo con nuestras encuestas, observamos que los rubros trabajo (54\%) y abasto (19\%) son los principales motivos de traslado. El 13\% representa a las amas de casa que llevan a sus hijos menores de edad a la escuela; particularmente en este rubro, las amas de casa nos explicaron que los tiempos de traslado les quitan demasiado tiempo para hacer otras actividades. El 9\% representa a los estudiantes de nivel medio superior, ocupado por mujeres que estudian y trabajan (Figura 4). 
FIgURA 3 | Principales destinos

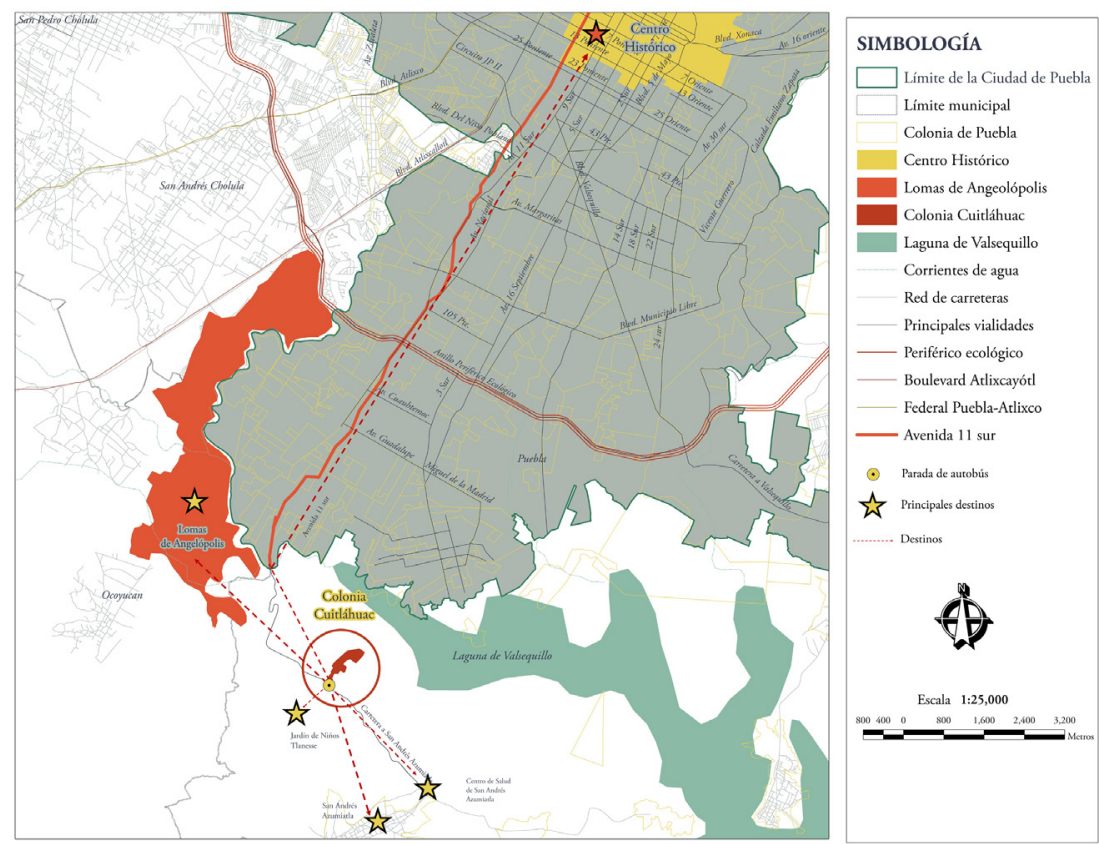

FUENTE: ELABORACIÓN PROPIA CON BASE EN EL MARCo GEOESTADÍSTICO DE PUEBLA (INEgi, 2020) E IMAGEN DE GOOGLE EARTH, 2020

\section{FIgURA 4 | Motivos de traslado}

Motivos de traslado

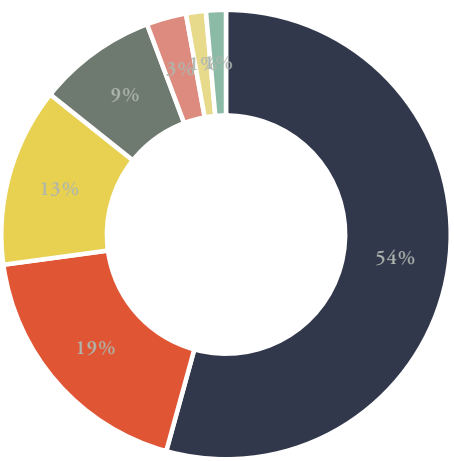

- Trabajo

- Abasto

- Llevar los hijos a la escuela

- Estudio

- Salud

- Esparcimiento

- No contestó

FUENTE: ELABORACIÓN PROPIA 
En Cuitláhuac, una familia formada por cuatro integrantes gasta en promedio el $23 \%$ de sus ingresos mensuales en transporte. Esto supera la media nacional, que indica que la población de las ciudades que vive en las zonas periféricas más alejadas gasta el $19 \%$ de sus ingresos mensuales en ese rubro (Instituto Mexicano para la Competitividad [Imco], 2018).

Las más afectadas por los altos costos del transporte son las madres al llevar a sus hijos a la escuela y trasladarse a otras actividades (principalmente trabajo y abasto). Ellas suelen buscar estrategias para minimizar los costos, aunque aun así son muy elevados respecto de sus ingresos. Un ejemplo claro lo encontramos en el siguiente testimonio de una madre joven, con tres hijos:

Cuando salgo a buena hora a dejar a mis hijos a la escuela, puedo llevarlos caminando; ni modo, trato de acostumbrarlos a que caminen un poco. Luego me gasto más de $\$ 50$ al día en puro camión, porque doy varias vueltas por otros mandados. Me gasto más de $\$ 300$ a la semana. (Com. pers., 4 diciembre 2018)

Al limitado transporte público, los altos costos, tiempos de espera y de traslado y las condiciones de marginalidad urbana en las que tienen que desplazarse los habitantes, se suman otras, como la mala calidad del servicio y la inseguridad dentro de las unidades del transporte público. Prueba de ello es lo que nos comentó uno de los pobladores:

Llevo viviendo cinco años en la colonia, y desde que llegué, si no es una cosa es otra: mis zapatos llenos de lodo, resbalarme en la parada cuando bajo del camión. Llego tarde a mi trabajo porque no me levanta el camión cuando va súper lleno; si me logro subir al camión, tengo que ir prácticamente con el pendiente de que no se llegue a voltear el camión en las curvas, que están muy peligrosas, sobre todo porque luego manejan como locos en ese tramo. Pero, te digo algo: me da más miedo cuando regreso tarde de trabajar; ese mismo tramo de las curvas está muy solo, ni siguiera hay luz para ver quién sube por ahí. (Com. pers., 19 noviembre 2018)

Mejorar la movilidad no es un asunto fácil, por lo que los habitantes se respaldan fuertemente en la organización Antorcha Campesina para tratar de mejorar sus condiciones, como se analiza a continuación.

\section{La presencia de Antorcha Campesina y la endeble acción gubernamental}

En Cuitláhuac, Antorcha Campesina ha estado presente de manera permanente y es la cabeza de la mesa directiva, formada por el presidente de la colonia (designado directamente por dicha organización), el tesorero, el secretario, ocho jefes de manzana (algunos jefes representan a más de una manzana) y un grupo de apoyo formado por diez adultos y seis niños. La mesa directiva representa la solidaridad comunitaria entre los vecinos, ya que a través de ella se organizan para realizar faenas cada domingo, destinadas al mejoramiento de la colonia (cortar pasto en calles, quitar maleza, nivelar las vías de acceso al lugar, recolectar basura, limpieza de cunetas, obras de autogestión sobre todo en temporada de lluvias, etcétera) o para atender problemáticas particulares de los vecinos (principalmente sobre la 
regularización y venta de lotes). Una de las vecinas que forma parte de la mesa directiva comentó al respecto:

Creo que es bueno lo que hacemos con las faenas; está bien para la colonia, porque se ve mejor y no da un aspecto malo (...). De alguna manera ayudan, porque conocemos a los vecinos para llevarnos bien y contar con alguien para tener confianza en pedir algún favor entre nosotros. (Com. pers., 11 febrero 2020)

Los habitantes tienen una relación directa con los jefes de manzana, quienes los representan en las reuniones semanales de la mesa directiva. A través de ellos hacen llegar sus principales demandas. El medio de comunicación entre el jefe de manzana y los habitantes es directo en las reuniones que realizan en función de sus necesidades (en promedio una vez al mes) o vía WhatsApp. En ocasiones, los jefes de manzana llegan a organizar reuniones invitando al presidente de la colonia para que los habitantes de su manzana tengan un contacto directo y fortalezcan sus lazos de confianza y solidaridad. No obstante, Antorcha Campesina permea su acción política durante las reuniones semanales, que incluyen a los nińos, donde destinan un tiempo para hablarles sobre la historia de esta organización, con la finalidad de hacerlos sentirse identificados con el movimiento e invitarlos a ser militantes activos de él. Con ello se trata de influir en la ideología política de los habitantes que, si bien luchan por el mejoramiento de las condiciones de vida de los sectores más desfavorecidos, también apoyan a sus líderes, quienes - de acuerdo con nuestras entrevistas- suelen negociar con las autoridades de turno diversos favores políticos. Las reuniones también sirven para verificar la asistencia de los habitantes a las marchas o a eventos de Antorcha Campesina.

Es mediante mítines y manifestaciones que los antorchistas de la colonia Cuitláhuac han ejercido presión a los poderes locales para satisfacer algunas de sus demandas. Hasta el momento han participado en diversas manifestaciones, entre las cuales está la demanda de transporte público, pero también lo han hecho en campańas proselitistas a favor de los candidatos de turno, principalmente de los partidos de derecha, Partido Revolucionario Institucional (PRI) y Partido Acción Nacional (PAN). También negocian directamente con los concesionarios de las rutas de transporte para que den el servicio sin traslaparse, aunque no siempre tienen buenos resultados. En este sentido, pudimos detectar que la presencia de Antorcha Campesina da seguridad y valor a los habitantes para enfrentar y presionar a las autoridades municipales, ya que muchos no cuentan con títulos de propiedad de sus tierras, por lo que si esta organización no estuviera presente, sería más difícil para ellos exigir sus derechos urbanos.

Para mejorar la movilidad, Antorcha Campesina creó en 2011 una estación de diez taxis que circulan sin permisos oficiales -es decir, son ilegales-, para dar servicio a diversos asentamientos del sector sur de la ZMPT pertenecientes a esta organización; entre ellos, Cuitláhuac. Tienen un costo de 10 pesos ( 0,50 usD) por persona (admiten hasta cinco personas), dan servicio desde las 6 de la mañana hasta las 12 de la noche, funcionan hasta la fecha y han sido bien aceptados por la población. En 2017 instauraron una estación de autobuses ubicada al exterior de la colonia, pero solo dio servicio durante un mes debido a que no contaba con 
autorización oficial, ya que era un acuerdo entre líderes antorchistas y concesionarios. Esto generó competencia a la única línea de transporte oficial, dotada por el municipio de Puebla, que circula al exterior de la colonia Cuitláhuac, dando lugar a constantes conflictos que a veces derivaban en riñas entre choferes. Además, los transportistas manifestaron que no era redituable este servicio, ya que nunca cubrían la capacidad máxima de sus unidades de transporte, que es de 40 pasajeros. Ante estas circunstancias, el conflicto y la baja demanda, optaron por dar de baja este servicio, desincentivando a los transportistas a volver a darlo, por lo que los líderes seccionales antorchistas no dieron continuidad a las acciones para satisfacer esta demanda.

A pesar de que Antorcha Campesina ha negociado con la autoridad municipal de Puebla el servicio de rutas alimentadoras en el sector sur, no siempre todos los asentamientos se han visto beneficiados. Particularmente, Cuitláhuac no ha tenido ningún beneficio hasta la fecha, lo que ha ocasionado la decepción de los habitantes, como se observa en los siguientes comentarios de los vecinos:

De qué sirvió que nos fuimos a parar a su ceremonia de inauguración, si ni alimentadoras nos van a mandar. Bien por los que les tocó, a la [colonia] Unión Antorchista; y a nosotros ¿para cuándo? o ¿qué van a hacer en la colonia? (Com. pers., 8 febrero 2018)

Como colonia, me di cuenta de que la Organización [Antorcha Campesina] nos exigen que apoyemos a su movimiento, pero no veo mucha ayuda de su parte; somos sus títeres, porque ellos nos piden, pero nos dan lo que les conviene. (Com. pers., 5 marzo 2020)

Además, existen bajas expectativas de los vecinos respecto del apoyo que puedan recibir de Antorcha Campesina para mejorar la movilidad, ya que esta organización no tiene una buena relación con la ruta de transporte que pasa cerca de la colonia, lo que lleva a vislumbrar como difícil la articulación y negociación con otras rutas para mejorar la movilidad hacia diferentes zonas de la ciudad. En este sentido, uno de los vecinos expresó lo siguiente:

Seguiremos con la Ruta S5, pues es la que hizo su monopolio. Lo que tendría que verse es que, en colaboración con otras rutas, se acoplen los trayectos hacia destinos más cercanos [...] pero la situación es difícil, pues a Antorcha Campesina no le conviene solucionar el problema, pues perderían influencia [control] en la colonia conforme vayan solucionando los problemas. Esto sucede en otras colonias que tienen los mismos problemas, pero igual los mantienen a largo plazo. (Com. pers., 23 noviembre 2019)

En el caso de Cuitláhuac, la falta de reconocimiento por parte del municipio de San Andrés Azumiatla, al cual pertenecían los terrenos en que se desarrolló la colonia, la ha situado en un estado de invisibilidad por parte de las autoridades. Cabe destacar que esta colonia se ha hecho visible en el municipio de Puebla en periodos electorales desde el año 2011, momentos que han constituido las únicas oportunidades para gestionar y obtener, por parte de este municipio, la escasa dotación de servicios con que cuenta. Esto ha llevado a alargar los procesos de dotación y/o mejoramiento 
de las infraestructuras y, por lo tanto, de la situación de vulnerabilidad de la colonia. Es notable que las acciones de Antorcha Campesina en favor de la Cuitláhuac hayan sido parciales y de largo plazo, ya que dar soluciones definitivas haría prescindible su presencia, anulando su capacidad de control.

\section{Mitigando la movilidad, la respuesta alternativa}

Ante las dificultades para moverse y llegar a sus diferentes destinos, los vecinos han desarrollado algunas formas de movilidad complementarias a las que implantó Antorcha Campesina, como el auto colectivo y el compartido.

La iniciativa del auto compartido tuvo su origen en dos vecinos, quienes propusieron acondicionar sus camionetas para trasladar a los estudiantes de jardín de niños, primaria y secundaria a bajo costo, 5 pesos ( 0,25 USD). Esta iniciativa fue apoyada por todos los vecinos de la colonia, surgió de manera esporádica y paulatinamente se ha ido consolidando. Establecieron un radio de servicio de $3 \mathrm{~km}$ (donde se encuentran los planteles educativos). Las camionetas se ubican en el centro de la colonia y tienen tres horarios matutinos de salida y dos vespertinos para ir a recoger a los estudiantes de jardín de niños y primaria. Los estudiantes de secundaria solo tienen el servicio de salida a las 6:40 a.m. ya que a esa hora la Ruta S5 no los acerca a su escuela. Para el regreso toman un transporte público que los deja a aproximadamente a 700 metros de la colonia.

Debido a que las camionetas no son para transporte público, sino que han sido 'acondicionadas' para llevar a los estudiantes, los trayectos son muy riesgosos. El acondicionamiento se limita a proteger a los vehículos de la lluvia y el sol, pero no hay asientos, y los niños y jóvenes, además de incómodos, van hacinados. Por lo anterior, han pedido a otros vecinos que tienen automóvil que ofrezcan su servicio para los estudiantes, gestión que no ha logrado una respuesta positiva debido a que lo consideran poco rentable. A pesar de esta situación, los residentes, aunque reconocen las malas condiciones físicas de este transporte, manifestaron sentirse seguros, ya que las personas que conducen son vecinos de toda su confianza.

Respecto al auto compartido, se trata de una iniciativa espontánea, pero habitual en la vida cotidiana de la colonia. Algunos habitantes propietarios de vehículos se ponen de acuerdo con sus vecinos para irse juntos (a decir de ellos, "darse el aventón”) y acercarse lo más posible a sus destinos o a las paradas de transporte público que más les convengan. También sucede que cuando los conductores ven a algún vecino en el camino, le ofrecen (si coincide con su trayecto) llevarlo o acercarlo a la parada de autobús. Los habitantes entrevistados coincidieron en que esta práctica no solo es un acto de apoyo entre vecinos, sino que también favorece sus relaciones sociales: "Después de que mi vecina me lleva hasta la parada de autobús, porque le queda de paso, hasta nos hablamos mejor. Antes cada uno iba por su lado" (Com. pers., 23 noviembre 2019).

También detectamos que hay buena disposición e interés para el uso de la bicicleta, principalmente por parte de la población joven. Sin embargo, no es una práctica habitual debido -como lo mencionamos anteriormente- a las malas condiciones físicas y falta de infraestructura vial de la colonia. Identificamos solo a dos jóvenes que la utilizan, cuyos trabajos se ubican a $6 \mathrm{~km}$, quienes nos dijeron que 
les ahorra tiempo (por lo menos la mitad del que les lleva hacerlo en transporte público) y dinero.

Por otro lado, la presencia de Antorcha Campesina logra inhibir la acción gubernamental para mejorar las condiciones de la colonia, pues cuando alguno de los miembros de la mesa directiva llega a hacer directamente la solicitud de servicios, ello difícilmente procede: estos se negocian directamente entre las autoridades y los antorchistas, como lo ratifica el siguiente comentario de uno de los vecinos:

Directamente con el gobierno podría ser [la dotación del servicio de transporte público], si la mesa directiva se acerca a alguna dependencia pública no habría problema. El problema es mencionar que es una colonia que pertenece a Antorcha, porque ya saben [los funcionarios públicos] que las negociaciones con ellos son de diferente manera. Entonces dan carpetazo y no sigue el proceso. Ellos tienen su manera de llegar a acuerdos. (Com. pers., 8 febrero 2020)

Debido a la nula respuesta gubernamental, las limitadas iniciativas de mitigación de los problemas y carencias que afectan a la movilidad que se han reseñado, y que se despliegan al margen de la ley, son la única alternativa que hasta el momento han encontrado los vecinos para resolver sus problemas de movilidad, y que además generan un ingreso adicional para aquellos que prestan el servicio.

\section{Conclusiones}

Con el estudio en Cuitláhuac demostramos que las competencias municipales continúan siendo rebasadas por el crecimiento urbano irregular, y que la falta de reconocimiento de los asentamientos irregulares por parte de la autoridad municipal agudiza su marginalidad urbana, complicando su movilidad y excluyéndolos de la ciudad consolidada. Esto limita tanto los modos de desplazamiento de sus habitantes como su movilidad cotidiana, la cual se enfoca principalmente a lo estrictamente necesario: empleo, abasto y educación.

El análisis nos ayudó a identificar dos razones fundamentales por las cuales los asentamientos irregulares no logran tener buenas condiciones para la movilidad y el servicio de transporte público: la primera es que ha resultado conveniente la falta de atención gubernamental, ya que muchas veces, mediante negociaciones con organizaciones como Antorcha Campesina, los gobiernos municipales logran manipular a los habitantes de estos asentamientos para obtener votos, a cambio de promesas de mejoramiento urbano, las cuales, cuando llegan a materializarse, suelen comprender solamente los servicios básicos. Así, la movilidad, cuando es atendida, se reduce a dar parte del servicio de transporte público, el cual se dificulta por las condiciones físicas de estos lugares; y en colonias como Cuitláhuac, llega a ser inaccesible. La segunda razón es que los criterios establecidos en los instrumentos gubernamentales para la regularización e incorporación de asentamientos irregulares al desarrollo urbano, los alejan del derecho a la urbanización. A esto se suma el hecho de que la planeación urbana local no ha logrado integrar los asentamientos periféricos a las zonas urbanas consolidadas ni asegurarles el salario indirecto, como lo demuestra nuestro estudio. Permanecen así en el rezago y la marginación durante 
tiempo indefinido, creándose brechas profundas en la planeación al alejarlos de un ordenamiento incluyente.

En el caso Cuitláhuac, la organización social muestra que ante las fuertes necesidades infraestructurales y de servicios urbanos, los habitantes han desarrollado formas articuladas de comunicación que incluyen desde el sector manzana hasta los líderes de la mesa directiva de la colonia, posibilitando con ello la creación de lazos solidarios para relacionarse y dar respuesta a sus necesidades fundamentales. Sin embargo, también encontramos que esta organización está controlada por Antorcha Campesina, lo que significa que las negociaciones con el gobierno para el mejoramiento de la colonia solamente se pueden realizar a través de dicha organización, inhibiendo la posibilidad de que los habitantes lo hagan directamente. Esto también se traduce en que el mejoramiento sea lento y largoplacista, pues la solución inmediata a los problemas significaría la pérdida de control de Antorcha Campesina en la colonia.

Las incipientes prácticas alternativas para la movilidad que han implantado los habitantes, aunque precarias e informales, suelen estar basadas instintivamente en los principios del desarrollo sustentable, ya que tratan de optimizar el uso del automóvil. Tales prácticas podrían ser aprovechadas y mejoradas, incorporándolas a las agendas públicas para ser reconocidas en el sistema de planeación local, y apoyadas para mejorar tanto las condiciones urbanas del asentamiento como las de los sistemas oficiales de transporte. Esto significaría un avance en la reconstrucción de la ciudad periférica marginal, sobre todo si se incluye a los vecinos organizados en los procesos para garantizar su funcionamiento en el largo plazo.

\section{Referencias bibliográficas}

Aguilar, A. G. (2002). Las mega-ciudades y las periferias expandidas. Ampliando el concepto en Ciudad de México. EURE - Revista Latinoamericana de Estudios Urbano Regionales, 28(85), 121-149. http://dx.doi.org/10.4067/S0250-71612002008500007

Alguacil Gómez, J., Camacho Gutiérrez, J. \& Hernández Ajá, A. (2014). La vulnerabilidad urbana en Espańa. Identificación y evolución de los barrios vulnerables. EMPIRIA - Revista de Metodología de Ciencias Sociales, (27), 73-94. https://doi.org/10.5944/ empiria.27.2014.10863

Bazant, J. (2004). Asentamientos irregulares. Guia de soluciones urbanas. Trillas.

Borja, J. (2014). Ciudad, urbanismo y clases sociales en perspectiva. PAPELES de relaciones ecosociales y cambio global, (26), 111-127. https://www.fuhem.es/papeles_articulo/ ciudad-urbanismo-y-clases-sociales-en-perspectiva/

Cámara de Diputados del H. Congreso de la Unión. (2018). Ley Agraria. Última Reforma 2506-2018. Diario Oficial de la Federación. México.

Consejo Nacional de Población (CONAPo), México. (2010). Indice de marginación por localidad. http://www.conapo.gob.mx/es/CONAPO/Indice_de_Marginacion_por_ Localidad_2010 
Córdova Morán, A. (s.f.). ¿Cómo trabajan los activistas de nuestro movimiento? Movimiento Antorchista Nacional. La organización de los pobres de México. http://www. antorchacampesina.org.mx/comotrabajamos.php

Da Cunha, A. (2005). Régime d'urbanisation, écologie urbaine et développement urbain durable: vers un nouvel urbanisme. En A. Da Cunha, P. Knoepfel, J. Leresche \& S. Nahrath, S. (Eds.), Enjeux du développement urbain durable. Transformations urbaines, gestion de ressourceset gouvernance (pp. 19-39). Presses Polytechniques et Universitaires Romandes.

Diario Oficial de la Federación (DOF), México. (2020). Ley General de Asentamientos Humanos, Ordenamiento Territorial y Desarrollo Urbano. Última reforma publicada en el Diario Oficial de la Federación el 6-01-2020. Cámara de Diputados del H. Congreso de la Unión. http://www.diputados.gob.mx/LeyesBiblio/ref/lgahotdu/LGAHOTDU_ ref02_06ene20.pdf

Fernandes, E. (2011). Regularización de asentamientos informales en América Latina. Lincoln Institute of Land Policy. https://issuu.com/colectivodelip/docs/1962_1283_ regularizacion_pfr_span_final

Flores Lucero, M. de L. (2016). Saneamiento en asentamientos irregulares en Puebla, un servicio postergado. En H. Quiroz Rothe (Comp.), Aproximaciones a la historia del urbanismo popular. Experiencias en ciudades mexicanas (pp. 297-312). Universidad Nacional Autónoma de México.

Flores Lucero, M. de L. (2017). The inexhaustible irregularity of the urban periphery of Puebla (Mexico). On the w@terfront, 50(2), 7-20. https://revistes.ub.edu/index.php/ waterfront/article/view/18668

Gobierno del Estado de Puebla. (2003). Ley de Desarrollo Urbano Sustentable del Estado de Puebla. Secretaría General de Gobierno. Orden Jurídico Poblano. http://www. ordenjuridico.gob.mx/Documentos/Estatal/Puebla/wo96597.pdf

Gobierno del Estado de Puebla y Ayuntamiento del Municipio de Puebla. (Actualización 2016). Programa Municipal de Desarrollo Urbano Sustentable (2014-2018). Secretaría de Desarrollo Urbano y Sustentabilidad. Dirección de Desarrollo Urbano. Instituto Municipal de Planeación. http://pueblacapital.gob.mx/images/transparencia/obl/viplanes/actua.prog.desa.urb.ru.pdf

Godoy Orta, M. G. (2014). Cultura politica democrática y organizaciones sociales. El caso de Antorcha Campesina. Tesis para obtener el título de Licenciada en Ciencias Políticas y Administración Pública, Universidad Autónoma del Estado de México. http:// ri.uaemex.mx/handle/20.500.11799/66132

Instituto Mexicano para la Competitividad A.C. (IMCo). (2018). Indice de movilidad urbana. Barrios mejor conectados para ciudades más incluyentes. https://imco.org.mx/indicemovilidad-urbana-2018-barrios-mejor-conectados-ciudades-mas-equitativas/

Instituto Nacional de Estadística y Geografía (INEGI), México. (2010). XII Censo General de Población y Vivienda. https://www.inegi.org.mx/programas/ccpv/2010/

Instituto Nacional de Estadística y Geografía (INEGI), México. (2020). Marco Geoestadístico. Puebla, México. https://www.inegi.org.mx/temas/mg/

Kunz Bolaños, I. \& González Herrera, G. (2019). ¿Es posible la gobernación metropolitana? Revista Mexicana de Ciencias Politicas y Sociales, 64(235), 463-494. https://doi. org/10.22201/fcpys.2448492xe.2019.235.61562 
Leibler, L. \& Brand, P. (2012). Movilidad e inclusión social: la experiencia desde la periferia de Medellín y el primer metrocable. Bulletin de l'Institut Français d'Etudes Andines, 41(3), 363-387. https://doi.org/10.4000/bifea.147

Luna, C. (2019). Zona metropolitana de Puebla reporta explosión urbana de 1,500\%. Entrevistado por J. Zambrano, Periódico Milenio, 03-02-2019. https://www. milenio.com/politica/comunidad/zona-metropolitana-puebla-reporta-explosionurbana-1-500

Mastretta, S. (2017). Grupos de poder en Puebla: La presencia de Antorcha Campesina en la ciudad de Puebla. En Mundo Nuestro. Periodismo narrativo. https://mundonuestro. $\mathrm{mx} /$ index.php/secciones/politica/item/1197-grupos-de-poder-en-puebla-la-presenciade-antorcha-campesina-en-la-ciudad-de-puebla

onu-Habitat. (2013). Planificación y diseño de una movilidad urbana sostenible: orientaciones politicas. Informe mundial sobre asentamientos humanos 2013. Resumen ejecutivo. Routledge. https://flacso.edu.ec/cite/onu-habitat_2013_planificacion-y-diseno-deuna-movilidad-urbana-sostenible-orientaciones-para-politicas/

Organización de las Naciones Unidas (onU). (2015). Objetivo 11. Ciudades y comunidades sostenibles. En Objetivos de desarrollo sostenible. https://www.un.org/ sustainabledevelopment/es/cities/

Organización de las Naciones Unidas (ONU). (2017). Nueva Agenda Urbana. Hábitat III. http:// uploads.habitat3.org/hb3/NUA-Spanish.pdf

Patiño Tovar, E. (2004). Periferia poblana: La desigualdad del crecimiento. Revista Papeles de población, 10(42), 143-145. https://www.redalyc.org/articulo.oa?id=11204206

Periódico Oficial del Estado de Tlaxcala. (2013). Actualización del Plan de Desarrollo de la Zona Metropolitana Puebla-Tlaxcala. Sintesis Ejecutiva N 33. Segunda Sección agosto 14 de 2013. Consejo de Desarrollo Metropolitano Puebla-Tlaxcala. http://periodico. tlaxcala.gob.mx/indices/Peri33-2a2013.pdf

Programa de las Naciones Unidas para el Desarrollo (PNUD). (2010, octubre). Gestión del riesgo urbano. Buró de Prevención de Crisis y Prevención.

Rey, C. \& Cardozo, O. (2007). La vulnerabilidad en la movilidad urbana. Aportes teóricos y metodológicos. En A. M. Foschiatti (Ed.), Aportes conceptuales y empiricos de la vulnerabilidad global (Cap. 11, pp. 397-425). Editorial de la Universidad Nacional del Nordeste (EUDENE). https://docplayer.es/2870712-Capitulo-11-la-vulnerabilidad-enla-movilidad-urbana-aportes-teoricos-y-metodologicos.html

Secretaría de Desarrollo Social (sedesol) \& Gobierno del Municipio de Puebla. (2012). Atlas de Riesgos Naturales del Municipio de Puebla. https://www.academia.edu/31106661/ Atlas_de_Riesgos_Naturales_Municipio_de_Puebla

Silverio Ramírez, J. C. (2017). Oferta de transporte público respecto a la urbanización del Municipio de Puebla. Tesis de Licenciatura, Facultad de Economía, Benemérita Universidad Autónoma de Puebla.

Sobrino, J. (2003). Zonas metropolitanas de México en 2000; conformación territorial y movilidad de la población ocupada. Estudios Demográficos y Urbanos, 18(3), 461-507. https://doi.org/10.24201/edu.v18i3.1156 
Susuki, H., Cervero, R. \& Iuchi, K. (2014). Transformando las ciudades con el transporte público. Integración del transporte público y el uso del suelo para un desarrollo urbano sostenible. Serie Desarrollo Urbano. Banco Mundial, Universidad de los Andes, Findeter (Financiera del Desarrollo Territorial). https://openknowledge.worldbank. org/handle/10986/12233

unión (2020). Observatorio laboral en México. Sueldos promedio en México por Estado. https:// www.unionpuebla.mx/articulo/2020/08/10/economia/observatorio-laboral-mexicosueldos-promedio-en-mexico-por-estado

Vázquez, J., Gamboa, A. \& Mendoza, M. (2015). Procedimientos técnico-administrativos para la regulación de un asentamiento humano irregular en la ciudad de Puebla. En M. Ramos-Escamilla \& D. Toscano-Ruiz (Eds.), Estrategias de desarrollo económico en Latinoamérica (pp. 98-110). Serie Tópicos Selectos de Economía, Vol. II. ECORFANEcuador. https:/www.ecorfan.org/ecuador/series/Serie_TSE_V_2\%20FINAL.pdf

Wilches-Chaux, G. (1989). La vulnerabilidad global. http://www.desenredando.org/public/ libros/1993/Idnsn/html/cap2.htm 